\title{
Annotations
}

\section{Pain relief}

\section{Do children feel pain?}

It is not so long ago that clinicians felt that 'children seldom need medication for the relief of pain after general surgery'. ${ }^{1}$ Twenty years ago in Chicago, only two out of 60 children received analgesia postoperatively. Similarly only 26 of the 180 children on an intensive care unit (where invasive procedures are common) received opiate analgesia. ${ }^{1}$ That children feel pain but do not complain of it was shown by Mather and Mackie who interviewed 170 children recovering from surgery. ${ }^{2}$ Seventy $(40 \%)$ reported moderate or severe pain on the day of the operation. Children would read or watch TV in order to distract themselves from the pain. They would therefore appear to be pain free, whereas on direct questioning they would confess to having pain. $^{2}$

Many theoretical reasons have been proposed as to why the newborn infant may not feel pain. ${ }^{3}$ Anand and co-workers, however, have shown that preterm babies in response to surgery have biochemical changes consistent with stress. ${ }^{4}$ These biochemical changes were reduced by administration of opiate analgesia (fentanyl). Also, babies receiving analgesia had fewer postoperative complications.

\section{Do doctors prescribe appropriate analgesia?}

Several studies have shown that it is not uncommon for children to have no analgesia prescribed postoperatively, even after major cardiac surgery. ${ }^{25}$ Children are more likely to be prescribed weaker analgesia than adults undergoing similar surgery. ${ }^{5} \mathrm{~A}$ recent questionnaire showed that although $80 \%$ of paediatric anaesthetists believe that neonates feel pain, only $11 \%$ would usually prescribe opiate analgesia after major surgery. ${ }^{6}$ Over $40 \%$ were reluctant to prescribe opiate analgesia for infants up to the age of 3 months. It is quite clear that many doctors are frightened of the clinical effects of opiate analgesia despite the paper by Anand and co-workers, which showed that opiate analgesia is not only safe but also actually reduces complications.

\section{Do nurses administer prescribed analgesia?}

Our fear of the effects of opiates in children has been conveyed to the nursing profession. In the study by Mather and Mackie, $39 \%$ of opiates prescribed were not given. ${ }^{2}$ In $29 \%$ of cases a weaker analgesic was given and it would appear that nurses feel it is safer for the patient to receive the less potent analgesic where more than one drug is prescribed. Adults received more than twice as many analgesics as children after major cardiac surgery. ${ }^{5}$ On the fifth postoperative day, 50 adults received a total of 136 doses of analgesics whereas an equal number of children received a total of 10 doses of analgesics. Children received on average two doses each day during the first three postoperative days. It is young children who suffer the most. The 12 children who received no analgesia postoperatively were all infants and toddlers. ${ }^{5}$

\section{Opiate infusions}

The use of a continuous infusion of morphine in children was first described by Miser et al in $1980 .^{7}$ Eight children with terminal malignancy and severe pain unresponsive to both oral and intermittent opiates were successfully treated with morphine infusions. Both children ${ }^{8}$ and adults ${ }^{9}{ }^{10}$ have less pain postoperatively when given a morphine infusion than with intermittent morphine. The safety of opiate infusions is shown by the experience in Perth where over 600 children have been treated and only one child required naloxone. ${ }^{11}$ The advantage of an infusion is that as well as preventing pain (rather than waiting for a patient to complain of pain and then administering analgesia), it also avoids painful intramuscular injections which for some children are as distressing as the pain itself.

\section{Are neonates and infants sensitive to opiates?}

There is some evidence to suggest that children under the age of 6 months are more sensitive to opiates. The newborn infant in particular may be more sensitive to respiratory depression with morphine than adults. ${ }^{12}$ Irregular breathing and seizures have been reported in infants and neonates 
receiving a morphine infusion. ${ }^{813}$ Other papers have, however, suggested that morphine is safe in the neonatal period. ${ }^{14-16}$ The neonate may also be more sensitive to fentanyl. ${ }^{17}$

\section{Morphine metabolism}

The half life of morphine in plasma is greater in newborn infants than in older infants because of reduced clearance. ${ }^{15}$ Lower doses of morphine in neonates would therefore appear to be rational. The situation is however complicated by the formation of morphine-6-glucuronide and morphine-6-sulphate, both active metabolites of morphine. Both are more potent analgesics than morphine in animals. ${ }^{18} 19$ Morphine-6-glucuronide is an effective analgesic when given to adults, ${ }^{20}$ and is present in plasma in higher concentrations than morphine itself after repeated oral administration of morphine. ${ }^{21}$ The formation of morphine-6-glucuronide is likely to be reduced in neonates as glucuronidation of other drugs is impaired in the neonatal period. Also, in vitro studies with fetal liver show a reduced ability to form morphine glucuronides. ${ }^{22}$ Little is known of the metabolism of morphine in neonates or children, or of the respective roles played by morphine, morphine-6-glucuronide, and morphine-6-sulphate in relation to analgesia and respiratory depression. As well as differences in the metabolism of opiates, animal studies have shown that opiate receptors may not be fully developed in the neonatal period. ${ }^{23}$

\section{Conclusion}

It is clear that the present management of pain relief in children can be improved considerably. Opiate infusions should be used more frequently in the postoperative period. Morphine is probably the drug of choice in that it has been used extensively and is both safe and effective. The protocol developed by Bray involves a morphine infusion of $20 \mu \mathrm{g} / \mathrm{kg} /$ hour, and if no opiate has been given with the premedication, an initial bolus dose of $200 \mu \mathrm{g} / \mathrm{kg}$. The infusion is usually required for 24 to 48 hours and the infusion rate adjusted for each individual patient.

Neonates receiving mechanical ventilation tolerate the same infusion rate of morphine $(20 \mu \mathrm{g} / \mathrm{kg} / \mathrm{hour})$ after surgery or painful procedures (for example, insertion of pneumothorax drain). For spontaneously breathing neonates, however, intensive monitoring must be utilised in view of the possibility of respiratory depression. ${ }^{24}$ In these babies and also in infants under the age of 12 months it is probably advisable to use an initial lower dose of morphine $(10 \mu \mathrm{g} / \mathrm{kg} /$ hour $)$ until our understanding of analgesia in infancy has improved.

Dr Choonara is an MRC Travelling Fellow.

\section{References}

1 Swafford LI, Allan D. Pain relief in the pediatric patient. Med Clin North Am 1968;52:131-6.

${ }^{2}$ Mather L, Mackie J. The incidence of postoperative pain in children. Pain 1983;15:271-82.

${ }^{3}$ Hatch DJ. Analgesia in the neonate. Br Med J 1987;294:920.

4 Anand KJS, Sippell WG, Aynsley-Green A. Randomized trial of fentanyl anaesthesia in preterm babies undergoing surgery: effects on the stress response. Lancet 1987;i:243-7.

${ }^{5}$ Beyer JE, DeGood DE, Ashley LC, Russell GA. Patterns of postoperative analgesic use with adults and children following cardiac surgery. Pain 1983;17:71-81.

6 Purcell-Jones G, Dormon F, Sumner E. Paediatric anaesthetists' perceptions of neonatal and infant pain. Pain 1988;33:181-7.

Miser AW, Miser JS, Clark BS. Continuous intravenous infusion of morphine sulfate for control of severe pain in children with terminal malignancy. J Pediatr 1980;96:930-2.

${ }^{8}$ Bray RJ. Postoperative analgesia provided by morphine infusion in children. Anaesthesia 1983;38:1075-8.

9 Church JJ. Continuous narcotic infusions for relief of postoperative pain. Br Med J 1979;i:977-9.

10 Rutter PC, Murphy F, Dudley HAF. Morphine: controlled trial of different methods of administration for postoperative pain relief. Br Med J 1980;280:12-3.

11 Dilworth NM, MacKeller A. Pain relief for the pediatric surgical patient. J Pediatr Surg 1987;22:264-6.

12 Way WL, Costley EC, Way EL. Respiratory sensitivity of the newborn infant to meperidine and morphine. Clin Pharmacol Ther 1965;6:454-61.

${ }^{13}$ Koren G, Butt W, Chinyanga H, Soldin S, Tan YK, Pape K. Postoperative morphine infusion in newborn infants: assessment of disposition characteristics and safety. J Pediatr 1985; 107:963-7.

14 Duncan A. The postoperative period. Clinics in Anaesthesiology 1985;3:619-32.

15 Lynn AM, Slattery JT. Morphine pharmocokinetics in early infancy. Anesthesiology 1987;66:136-9.

16 Purcell-Jones G, Dormon F, Sumner E. The use of opioids in neonates. A retrospective study of 933 cases. Anaesthesia 1987;42:1316-20.

17 Koehntop DE, Rodman JH, Brundage DM, Hegland MG, Buckley JJ. Pharmacokinetics of fentanyl in neonates. Anesth Analg 1986;65:227-32.

${ }^{18}$ Shimomura K, Kamata O, Ueki S, et al. Analgesic effect of morphine glucuronides. Tohoku J Exp Med 1971;105:45-52.

${ }^{19}$ Mori M, Oguri K, Yoshimura H, Shimomura K, Kamata O, Ueki S. Chemical synthesis and analgesic effect of morphine ethereal sulfates. Life Sci 1972;11:525-33.

${ }^{20}$ Osborne R, Joel S, Trew D, Slevin M. Analgesic activity of morphine-6-glucuronide. Lancet 1988;i:828.

21 Säwe J, Svensson JO, Rane A. Morphine metabolism in cancer patients on increasing oral doses-no evidence for autoinduction or dose-dependence. Br J Clin Pharmacol 1983;16:85-93.

22 Pacifici GM, Säwe J, Kager L, Rane A. Morphine glucuronidation in human fetal and adult liver. Eur J Clin Pharmacol 1982;22:553-8.

${ }^{23}$ Leslie FM, Tso S, Hurlbut DE. Differential appearance of opiate receptor subtypes in neonatal rat brain. Life Sci 1982;31: 1393-6.

24 Yaster M. Analgesia and anesthesia in neonates. $J$ Pediatr 1987;111:394-6.

I A Choonara Division of Clinical Pharmacology, University Hospital, S-75185 Uppsala, Sweden 